Beverley A. O rser PhD MD FRCPC, Robert J.B. Chen BSC MD FRCPC, Doreen A. Yee MD FRCPC

\title{
M edication errors in anesthetic practice: a survey of 687 practitioners
}

Purpose: The objectives of this study were to determine: 1) if anesthesiologists had experienced a medication error and 2) to identify causal factors. The perceived value of a Canadian reporting agency for medication errors and improved standards for labels on drug ampoules was also investigated.

M ethods: A self-reporting survey was mailed to members of the $C$ anadian Anesthesiologists' Society $(n=2,266)$. Respondents provided free-text descriptions of medication errors and answered fixed response questions.

Results: Surveys from 687 anesthesiologists (30\% response rate) revealed that $85 \%$ of the participants had experienced at least one drug error or "near miss". Although most errors $(1,038)$ were of minor consequence $(98 \%)$, four deaths were reported. The commonest error involved the administration of muscle relaxants instead of a reversal agent. "Syringe swaps" (70.4\%) and the misidentification of the label (46.8\%) were common contributing factors. Anesthesiologists (97.9\%) reported that they read the ampoule label "most of the time" although the label colour was an important secondary cue. Approximately half of the participants would report the error if a reporting program existed and $84 \%$ agreed that improved standards for drug labels would reduce the incidence of error.

Conclusions: Most anesthesiologists experienced at least one drug error. The commonest error was a "syringe swap" that involved a muscle relaxant. Most errors were of minor consequence, however, serious morbidity and mortality resulted from clearly preventable events. These results support the develo pment of improved standards for drug labels and the establishment of a Canadian reporting program for medication errors.

Objectif : 1) Découvrir si les anesthésiologistes ont vécu l'expérience d'une erreur de médication et 2) en déterminer les facteurs de causalité. Aussi, on a étudié la valeur perçue d'une agence de notification canadienne des erreurs de médication et de normes strictes des étiquettes d'ampoules de médicaments.

M éthode : U ne enquête d'autodéclaration a été postée aux membres de la Société canadienne des anesthésiologistes $(n=2,266)$. Les répondants ont fourni des descriptions en textes libres des erreurs de médication et ont répondu aux questions à réponses fixes.

Résultats : Les réponses reçues de 687 anesthésiologistes (taux de réponse de $30 \%$ ) ont révélé que $85 \%$ des participants avaient fait au mo ins une erreur de médicament ou l'avait évitée de justesse. Même si la plupart des erreurs $(1,038)$ n'ont eu que des conséquences mineures $(98 \%)$, quatre décès ont été rapportés. L'erreur la plus fréquente concernait l'administration de myorelaxants à la place de décurarisants. "L'échange de seringue" (70,4\%) et la mauvaise identification de l'étiquette $(46,8 \%)$ étaient souvent des causes d'erreur. Certains $(97,9 \%)$ ont dit lire l'étiquette sur l'ampoule "la plupart du temps" même si la couleur de l'étiquette était un important signal secondaire. La moitié des participants environ auraient mentionné l'erreur si un programme de notification avait existé et $84 \%$ croyaient que des normes plus strictes d'étiquetage des médicaments pouvaient réduire l'incidence d'erreur.

Conclusion : La plupart des anesthésiologistes ont expérimenté au moins une erreur de médicament. L'erreur la plus fréquente a été "l'échange de seringue" pour un myorelaxant. Même si, en général, les conséquences sont mineures, une morbidité et une mortalité préoccupantes ont découlé d'incidents qu'on aurait pu certainement prévenir. Ces résultats incitent la mise au point de normes plus strictes pour l'étiquetage des médicaments et l'établissement d'un programme canadien de notification des erreurs de médication.

From the D epartment of Anesthesia, Sunnybrook and Women's College H ealth Science Centre, U niversity of Toronto, 2075 Bayview Avenue, Toronto, Ontario, M 4N 3M 5 Canada.

A ddress correspondence to: Dr. B. O rser. Phone: 416-978-0574; Fax: 416-978-4940; E-mail: beverley.orser@utoronto.ca

A ccepted for publication October 22, 2000. 
M

EDICATIO N error is a leading cause of morbidity and mortality in hospitalized patients. $^{1}$ An estimated 180,000 patients die in the U nited States each year as a result of adverse medical events and medication error is a leading contributing factor. To place this mortality rate in context, the number of medical errorrelated death far exceeds the mortality associated with automobile crashes $(45,000) .{ }^{2}$ In addition to personal loss, adverse drug events impose a considerable financial burden to health care systems. The annual cost of medication-related problems in one university hospital was estimated to be $\$ 1.5 \mathrm{M}$. $^{3}$ Thus, effective strategies that reduce medication error would enhance patient safety and represent a cost-savings opportunity.

The incidence of medication error associated with anesthetic practice is not certain. $\mathrm{H}$ owever, given the potency, variety, and frequency of the drugs adminis tered to patients undergoing anesthesia, the potential exists for errors with disastrous consequences. N ot surprisingly, several studies indicate that medication error is a common adverse event in patients undergoing anesthesia. ${ }^{4}$ Another study reported that the incidence of medication error was secondary only to the incidence of airway-related mishaps. ${ }^{5}$ Analysis of critical incidences by Cooper and colleagues showed that the number of drug-related events far exceeded the next most common problem, disconnection of the breathing circuit. ${ }^{6}$ The Australian Incident Monitoring Study analyzed adverse events during anesthesia and reported that, "the wrong drug" was the most common adverse event. ${ }^{7}$ Indeed, anesthetic drug errors have been reported for every aspect of anesthetic-related care. ${ }^{8-11}$

The current study arose from the recommendations resulting from the risk-management analysis of a nearfatal anesthetic drug error. ${ }^{12}$ The error involved the administration of epinephrine instead of glycopyrrolate. The review panel proposed the following changes: 1) education to increase awareness regarding the risks of medication errors; 2 ) a review of the standards for the labeling and packaging of drug ampoule and vials; 3) development of a national reporting program for drug errors and 4) research to identify effective strategies that reduce the incidence of medication error.

The purpose of this study was to determine the frequency and cause of medication errors in patients undergoing anesthesia. Anesthesiologists were asked to describe medication errors or "near-misses" in order to identify the common causal or contributing factors. H ere we define a "near miss" as an event that did not involve the actual administration of a drug. In addition, practitioners were asked if they would report the error to national reporting agency and whether improved standards for drug labels would reduce the incidence of drug error.

\section{M ethods}

A self-reporting survey was designed by the authors in collaboration with members of the Department of Biostatistics and Epidemiology, Sunnybrook $\mathrm{H}$ ealth and Women's College Health Science Centre, and the Labeling Committee of the Pharmaceutical $M$ anufacturing Association of Canada. (Appendix). The survey was composed of four sections. The first section requested information concerning the number of years of anesthetic training, the percentage of time spent administering anesthetics, the level of training (F ellow of the Royal College of Physicians and Surgeons of Canada or equivalent national certification) and the location of the practice. The second section asked if the respondent had ever administered the wrong drug during the conduct of an anesthetic. The survey form provided space for a free-text description of the incident and associated outcome. The outcome of the error was ranked as being of no clinical significance, minor morbidity, major morbidity or death. Potential contributing factors were listed and respondents were asked to identify the factors that were relevant to the incident. More than one factor could be identified for each event. In the third section, anesthesiologists were asked to indicate the features of the label and package that they considered important for drug identification. Finally, respondents were asked if, and to whom, the errors were reported. If the event had not been reported, they were asked to provide an explanation. The survey was mailed along with a stamped, self-addressed envelope and letter of explanation to every member of the Canadian Anesthesiologists' Society that was registered in 1995. The respondents were assured of anonymity. A postcard that reminded the members to return the survey was mailed eight weeks later. $M$ embers were also questioned nine months later at the $53 \mathrm{rd}$ meeting of the C anadian Anesthesiologists' Society and asked to complete the survey, if they had not already done so.

The research nurse and an anesthesiologist (RJC) analyzed the data. The results are expressed as absolute numbers and percentages.

Results

Surveys were mailed to all the members of the Canadian Anesthesiologists' Society that were registered in $1995(n=2,266)$. A total of 687 surveys were returned for analysis (30\% response rate) and 1,038 drug-related events were described. The average number of events per responder was 1.5.

The demographic profile of the participants is summarized in Figure 1. Most responders had practiced 
anesthesia for 5 - $10 \mathrm{yr}$ and were trained as specialists in anesthesia (FRCPC or equivalent certification). Respondents usually practiced in university-affiliated teaching hospitals and spent greater than $75 \%$ of their professional time providing clinical care.

A total of 1,038 adverse events were described; $61.7 \%(n=424)$ of responders reported actual errors while $9.6 \%(n=66)$ reported "near misses". A "near miss" is an event in which the drug was not actually administered. $\mathrm{N}$ inety-five of the respondents (13.98\%) described both an actual error and "near miss", while a similar number 103 (14.9\%) reported that they had never experienced an error (Figure 2 ).

The reported outcomes of the drug errors are described in Figure 3. The majority of the adverse events were either of minor consequence, $(35.4 \%, \mathrm{n}=$ $368)$, or no clinical importance, $(57.5 \% \mathrm{n}=597)$. Fifteen drug errors (1.4\%) resulted in major morbidity (including cardiac arrest, stroke or permanent injury) and four deaths were reported $(<0.4 \%)$. The deaths resulted from an overdose of ketamine due to the misidentification of a $50 \mathrm{mg} \cdot \mathrm{ml}^{-1}$ vial instead of 10 $\mathrm{mg} \cdot \mathrm{ml}^{-1}$ vial, administration of norepinephrine instead of fentanyl for sedation in the intensive care unit, potassium chloride solution used to dilute an antibiotic; and peritoneal dialysate infused intravenously for volume resuscitation. A description of the most frequent nonfatal errors is provided in Table I.

The misidentification of a syringe or "syringe swap" was the most common cause of error $(70.4 \%, n=413$, Tables I, II). 0 ther contributing factors included a failure to read the label $(62.9 \%, n=367)$, and misidentification of the drug ampoule or vial $(46.8 \%, \mathrm{n}=274)$.

When asked, "In your estimation, how often do you actually READ the drug name on the label if you are working in your usual workplace?" surprisingly most anesthesiologists reported that they do so only infrequently ( $T$ able III). M any responders identified colour as the single most important feature used to identify drugs (Table IV). Of lesser importance was the drug name and the size and shape of the container. When asked to rate the importance of certain feature(s) of the package and label they used for identification, colour was the most frequent response. Surprisingly, the colour of the ampoule and its label were cited as "extremely important" for ampoule recognition. Similarly, the colour of a vial and cap were considered "extremely important". For prefilled syringes, the text colour and external packaging were considered "extremely important". For self-prepared syringes, the syringe size and drug label were the most important features. O ther features that were not considered as important included needle gauge and leav-
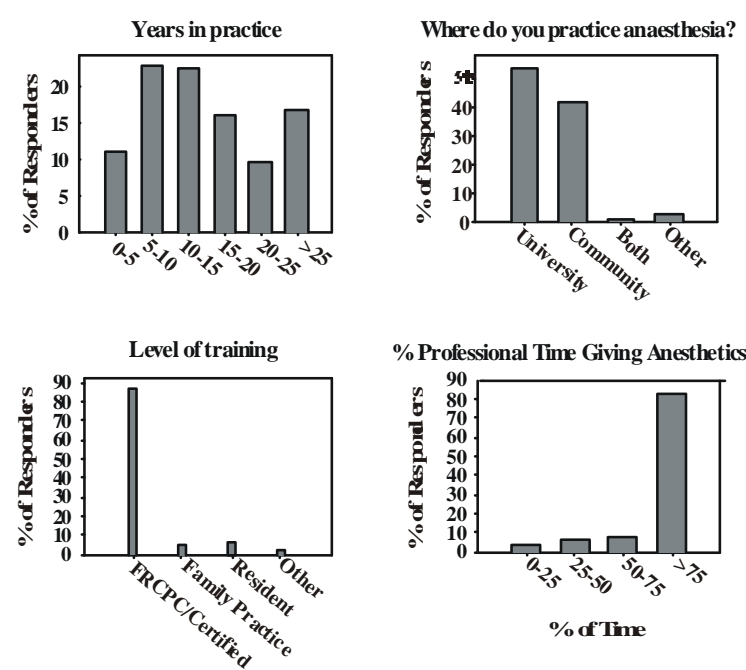

FIGURE 1 Demographics of the responders

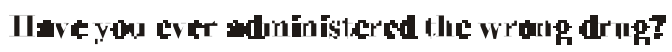

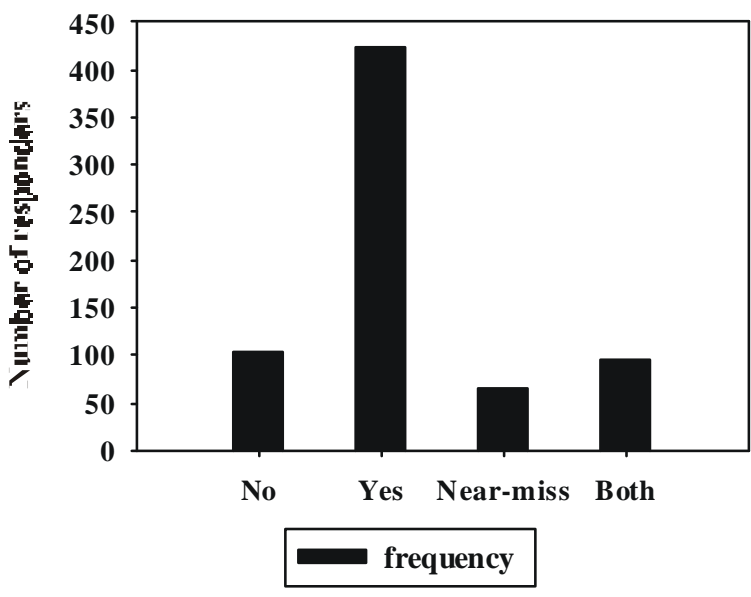

FIGU RE 2 O ccurrence of medication errors

ing the needle inserted into the drug vial or ampoule.

M ost anesthesiologists $(86.5 \%=594)$ were aware of the self-adhesive, user applied drug labels that were developed by the Canadian Standards Association International (CSA, Standard Z264.3-98) for anesthesia and critical care. However, only $72 \%(n=495)$ of respondents that were aware of the self-adhesive labels, used them regularly. When asked if they believed these labels decrease the incidence of drug errors, $86.9 \%(n=$ 597) "agreed" or "strongly agreed". A similar proportion "agreed" or "strongly agreed" that improved stan- 


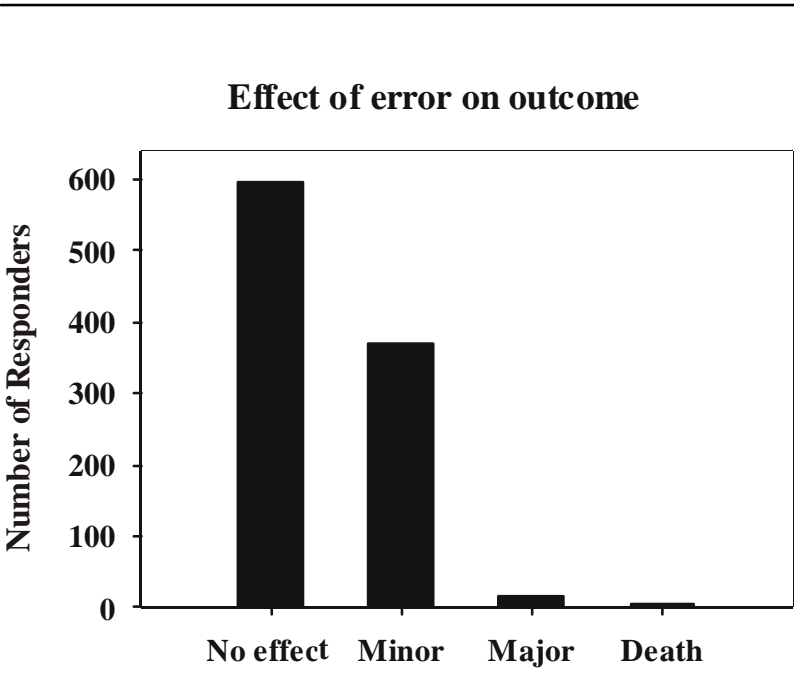

FIGURE 3 Outcome of the medication error

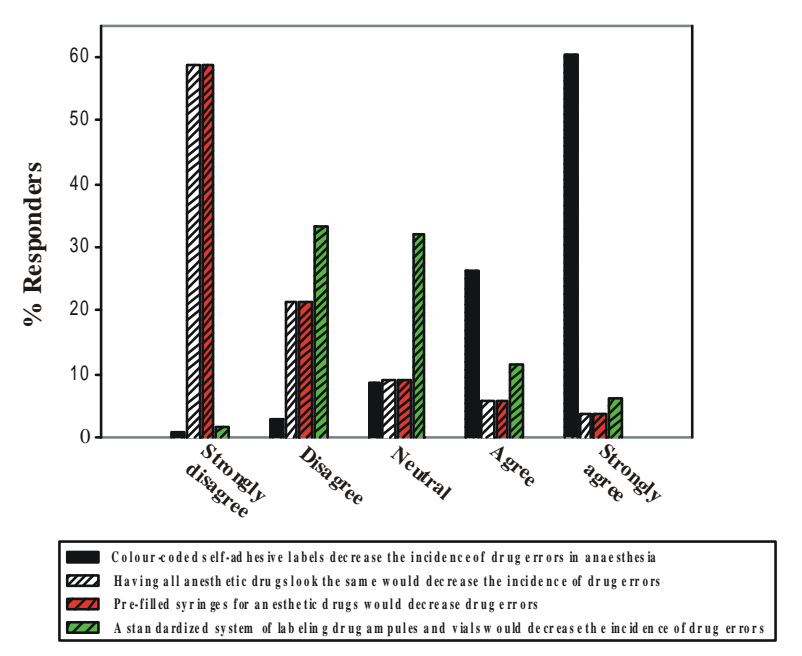

$\overline{\text { FIGU RE } 4 \text { Respondent's opinion of strategies to reduce medica }}$ tion error.

dardized labels would decrease the incidence of medication error $(83.8 \%, n=576)$. O nly $9.5 \%(n=65)$ felt that having all anesthetic-related drugs similarly labeled and packaged would reduce errors (Figure 4). Most participants did not agree that strategies such as prefilled syringes $17.3 \%(n=119)$ would reduce the number of errors.

The majority of errors identified in the survey have not been reported elsewhere $60.1 \%(n=423)$. Practitioners reported the errors to colleagues $(10.4 \%$, $\mathrm{n}=72)$, attending staff at teaching centers $(10 \%, \mathrm{n}=$
TABLE I Frequency of errors

\begin{tabular}{lll}
\hline \multicolumn{1}{c}{ M ost frequent errors } & & \\
Causes & Percentage (\%) & (n) \\
\hline $\begin{array}{l}\text { N on-depolarizing muscle relaxant } \\
\quad \text { when reversal intended }\end{array}$ & 13 & 132 \\
$\begin{array}{l}\text { Succinylcholine when opioid intended } \\
\begin{array}{l}\text { O pioid when non-depolarizing muscle } \\
\quad \text { relaxant intended }\end{array}\end{array}$ & 5 & 52 \\
$\begin{array}{l}\text { Inotrope swapped for another inotrope } \\
\begin{array}{l}\text { Inotrope when anticholinergic } \\
\quad \text { was intended }\end{array}\end{array}$ & 3.3 & 51 \\
\hline
\end{tabular}

TABLE II Contributing factors

\begin{tabular}{ll}
\hline \multicolumn{1}{c}{ Factors contributing to error } & \\
Factors & Percentage (\%) \\
\hline Syringe swap & 60 \\
Did not read label & 53 \\
M isidenification of ampoule/ vial & 39 \\
Drug incorrectly stocked & 18 \\
Wrong dose injected & 10 \\
\hline
\end{tabular}

* Percentages do not sum to $100 \%$ because responders often reported more than one factor

TABLE III Reading the label

\begin{tabular}{ll}
\hline Choices & H ow often do you read the label? \\
& Percentage (\%) \\
\hline N ever & 0 \\
Sometimes & 4.6 \\
M ost of the time & 47.3 \\
Always & 47.6 \\
\hline
\end{tabular}

\section{TABLE IV FEATURES FOR IDENTIFICATION}

\begin{tabular}{ll}
\hline \multicolumn{2}{c}{ The singlemost important feature of the label } \\
Choices & Percentage (\%) \\
\hline There is N OT one feature on the label & \\
... that helps me... & 26.9 \\
Colour of text, label, vial, ampoule or cap & 50.7 \\
D rug name or label & 7.5 \\
Shape of container & 7.1 \\
Size of container & 3.4 \\
Drug location, syringe codes & $<1$ \\
\hline
\end{tabular}

$69)$ or at departmental meetings or rounds $(7.5 \%, \mathrm{n}=$ 52). No errors were reported to provincial or national health agencies. When asked why the errors were not reported, the most common response was that the error was inconsequential $(68.3 \% n=469)$. A further $18 \%(n$ $=122$ ) of anesthesiologists were not certain where or to whom the error should be reported. A smaller number of practitioners cited medico-legal concerns ( $n=40$, 
$6.0 \%$ ) or concerns regarding the opinion of their colleagues $(5.7 \%, n=38)$. M ost patients $(83.5 \%, n=867)$ were not informed of the drug error. When asked, "If there were a single reporting agency for anesthetic drug errors, would you have reported the error(s) to this agency?", 234 respondents of 507 (46.1\%) agreed that they would report the error. It should be noted that the type of reporting program (e.g., anonymous versus mandatory, self-reporting was not defined in the survey.

\section{Discussion}

This report describes the largest number of medication errors in patients undergoing anesthesia that has been published to date. M ost anesthesiologists experience at least one actual or potential medication error while in clinical practice. The study confirm several findings from previous reports. ${ }^{7,13} \mathrm{~N}$ otably, most errors were of minor consequence and resulted in no harm to the patient. However, four deaths were reported. The most common medication error was a "syringe swap" that involved the administration of a neuromuscular relaxant when an anticholinesterase was intended. Factors that frequently contributed to other errors included "syringe swap" and misidentification of the ampoule or vial.

Eighty-six percent of respondents were aware of the self-adhesive labels designed by Canadian Standards Association International, but of this group, only $72 \%$ used them. Therefore, almost $40 \%$ of the responders do not use standardized syringe labels. M ost anesthesiologists read drug labels "most of the time" but surpris ingly few consider the drug name to be the most important feature used to identify a drug. More than $25 \%$ of the responderts reported that there was not a single feature used for identification, rather, an assembly of distinct characteristics was used to identify a drug. For example, one respondent stated that the drug ampoule was identified, "like a face", not by individual elements but rather the whole presentation. Although most of the errors were felt to be of minor consequence, many anesthesiologists were unsure of where or to whom, the events should be reported.

The limitations of a self-reporting survey as a research tool to investigate medication errors are noteworthy. Participants were self-selected and may only report errors they judged to be of sufficient interest or consequence. This introduced a non-responder bias. Also, anesthesiologists may have been reluctant to report all their mistakes. U ndoubtedly, the number of errors reported by individual participants was likely low. M ost importantly, the M ethods do not allow the incidence of error to be determined (as the denominator or number of anesthetics administered is not known). Such limitations could be minimized in prospective studies. Nevertheless, our findings are stimulating and present anesthesiologists with a challenge. $\mathrm{O} \mathrm{n}$ the one hand, the occurrence of medication errors was extremely low, given the number of drugs that were likely administered by the respondents. $\mathrm{H}$ owever, rare events were associated with major morbidity and mortality. The cause of the fatal errors were as diverse as the problems the drugs were intended to treat. In the face of such complexity, how can the medication delivery system be designed to enhance patient safety?

The specialty of anesthesiology has provided leadership in the development of safety standards and analyzing human factors that contribute to error. Because the potential for harm is so great, anesthesiologists are well positioned to "champion the cause" to design and implement safeguards for the medication delivery system. I mmediate interventions need to be targeted to individual practitioners. For example, it is essential to educate and raise awareness about the risks of medication error. As standard curriculum, clinical trainees should be informed about the cost of medical error, particularly medication-related adverse events. The concept, "Read The Label" cannot be overemphasized. Also, high-risk drug interventions, such as the administration of an anticholinesterase to reverse muscle relaxants, need to be recognized. $\mathrm{H}$ owever, as stated by James Bagian, a former space shuttle astronaut who was involved in the analysis of the Challenger explosion, "J ust telling doctors and nurses to be more careful won't do much. We need to change the systems that allow errors to happen". ${ }^{14}$

What additional practical strategies can be implemented to combat medication errors? Punitive strategies are short-sighted and fail to identify the systematic deficiencies that predispose to error. $\mathrm{N}$ evertheless, in some jurisdictions, health care professionals have been convicted of criminal charges as a result of a medication error. ${ }^{15}$ Indeed, in C anada, several recent deaths from medication errors were considered to be homicide. Are all anesthesiologists at risk of such criminal charges? It is the opinion of the authors and many other stakeholders (including the Institute of Safe M edication Practice, www.ismp.org) that mandatory reporting and blame-oriented approaches do little to remedy the problem.

In a recent landmark publication entitled, "To Err is H uman: Building a Safer H ealth System", strategies to reduce medical errors were proposed. ${ }^{16}$ This report was released by the Institute of $M$ edicine $Q$ uality of $\mathrm{H}$ ealth $\mathrm{C}$ are $\mathrm{C}$ ommittee of the $\mathrm{N}$ ational Academy of Science of the $U$ nited States. The specialty of anesthe- 
siology was cited at least 10 times in the text, in reference to effective interventions adopted by the specialty to increase safety. The report recommended that a Center for Patient Safety be created that would be charged with defining goals, understand why errors occur, and developing a research agenda. M ethods to identify and prevent errors and to communicate safety activities are to be developed. The report also recommended improved labeling and packaging standards. The President of the $U$ nited States, Bill Clinton, endorsed this report and the U.S. Congress was charged with implementing several of the recommendations this year.

At the national level in Canada, several initiatives aimed at reducing medication errors are being developed. A new standard for the labels on ampoules, vials and prefilled syringes for parenteral compounds has recently been published by the $C$ anadian Standards Association International (CAN / CSA-Z264.2-99). ${ }^{17}$ The purpose of the standard is to define a minimal performance level and to demand consistency across the pharmaceutical industry. The standard also focuses greater attention on patient safety and defines the performance expectation of health care providers. The objective of the standard was to make labels as legible and unambiguous as possible and address concern that labels were not designed with safety as a primary goal. ${ }^{18} \mathrm{~T}$ o date, this standard is not a mandatory regulation and, thus, requires the support of health care professionals. Results of this study suggest that practitioners support improved labeling standards. Consequently, anesthesiologists should demand that medications used in the operating room comply with the standard set by Canadian Standards Association International. Group purchasers have more influence than single practitioners and this demand should be directed to the hospital pharmacists.

Almost half of the participants indicated they would report the error to a national reporting program for medication errors although such a Canadian program does not exist. However, a non-profit organization modeled after ISMP in the U nited States is under development. The I nstitute of Safe M edication Practice of Canada (ISM P-Canada, www.ISM P-Canada.org), serves as an anonymous practitioner-based reporting program that will collect, analyze and disseminate information regarding medication errors. Practitioners are encouraged to forward reports of errors to this organization. Future research should be directed at the effectiveness of practical, "common-sense" interventions including techniques that reduce reliance on memory, standardization, the use of protocols and checklists, and the elimination of look-alike products.
In summary, this study demonstrates that most anesthesiologists will commit a medication error. This finding is not surprising because the potential for medication error increases as the number of drugs administered increases. ${ }^{19}$ The data contradict public opinion that views medical mistakes as an individual provider issue. ${ }^{20}$ When asked to identify solutions to prevent medical mistakes, $75 \%$ of respondents selected, "keeping health care professionals with bad track records from providing care". Clearly, remedial approaches that simply blame practitioners must be tempered and effective safeguards built into medication delivery systems.

\section{Acknowledgments}

The authors wish to thank to the members of the Canadian Anesthesiologists' Society (CAS) that returned the survey. The CAS generously allowed the survey to be mailed together with a $\mathrm{N}$ ewsletter. The project was funded by an award to BAO and DY from Glaxo-Wellcome Incorporated. A Career Scientist Award from the Ontario Ministry of $\mathrm{H}$ ealth and $\mathrm{CIHR}$ support Dr. Orser's research. We thank Dr. Keith Rose for a critical review of the manuscript and $\mathrm{Mr}$. Ali Roussli for assistance with the preparation of the figures. M s. Ellen H arrington R.N. assisted with the data analysis.

\section{Appendix}

\section{DRUG ERRORS IN ANESTHETIC PRACTICE: ROLE OF LABELING AND PACKAGING}

A. Your Anesthetic Practice Profile

1. H ow many years have you practiced anaesthesia (including residency)?

2. Approximately what percent of your professional time is spent administering anaesthetics?

3. What is your training? FRCPC/ Board-certified Family practice anesthesia Resident-in-training $O$ ther: Explain

4. Where do you practice anesthesia? $U$ niversity Teaching $C$ enter Community $\mathrm{H}$ ospital $O$ ther: Explain

B. Prevalence of D rug Errors in Anesthetic Practice 1. In the course of administering anesthesia, have you ever given the wrong drug to a patient?

YES [Please elaborate in question 2] ALM OST (i.e. "near miss") 
[Elaborate in question 2] NO [Proceed to Section C ]

2. $N$ ame the drug(s) involved and describe the clinical effects. (e.g. what drug you intended to give, what drug patient received) $U$ se extra sheet to describe if necessary.

\section{EVENT 1}

\section{EVENT 2}

\section{EVENT 3}

3. Did any of the factors listed below contribute to these drug errors? If yes, check one or more box for each event.

M isidentification of Ampoule/ Vial EVENT NUMBER $M$ islabeling of Syringe

'Syringe Swap' (wrong syringe injected)

Did N ot Read Label

Incorrect D rug Injected Stocked in

Wrong Location

Wrong D ose of D rug I njected

O ther (please elaborate below)

Comments:

4. In your opinion, what was the effect of each error on outcome? (Check one box for each event.) EVENT NUMBER

Of N o Clinical Significance 123

$M$ inor M orbidity (required immediate intervention to prevent permanent injury)

M ajor M orbidity (e.g. cardiac arrest, stroke

or permanent injury)

D eath (only cause or contributory)

Comments:

C. Features of D rug Labeling and Packaging

1. In your estimation, how often do you actually REA D the drug name on the label if you are working in your usual workplace?
a. never
c. most of the time
b. sometimes
d. _-_-_ always

2. What is the single most important feature of the label or container that helps you identify a drug used in the $\mathrm{O} \mathrm{R}$ or critical care setting on a daily basis? a. tainer or cap that helps me identify a drug.

b. That one feature is:

3. Rate the importance of the following packaging features in assisting identification of anesthetic drugs. [i.e. What characteristics of a drug vial or ampoule direct you to pick that container out from your drug cart when drawing up anaesthetic drugs?] Check off one box for each line.

$0=$ not important

$1=$ somewhat important

$2=$ moderately important

3 = extremely important

A mpoules

Color of Ampoule

$\begin{array}{llll}0 & 1 & 2 & 3\end{array}$

Label Colours

Text Size

Text Font

Color Banding on Snap-off Portion

Size of Ampoule

Vials

Colour of Vial

$\begin{array}{llll}0 & 1 & 2 & 3\end{array}$

Cap Colour on Vials

Text Color

Text Size

Text Font

Size of Vial

Shape of Vial

Prefilled Syringes

Text Colour

Text Size

Text Font

Size of Syringe

External Packaging (e.g. box)

Self-prepared Syringes
Size of Syringe U sed for Specific D rug

Gauge (Colour) of N eedle on Syringe

D rug Label

L eaving needle of syringe in opened

drug ampoule or vial

4. Are you aware of the availability of colour-coded, CSA standardized labels for anaesthetic drug syringes?

YES NO

5. If yes, do you use these colour-coded self-adhesive labels?

YES NO

6. Please indicate your agreement/ disagreement with the following by circling a number for each statement:

$$
\begin{array}{ll}
\text { Strongly } & \text { Strongly } \\
\text { Disagree } & \text { Agree }
\end{array}
$$

a. Colour-coded self-adhesive 


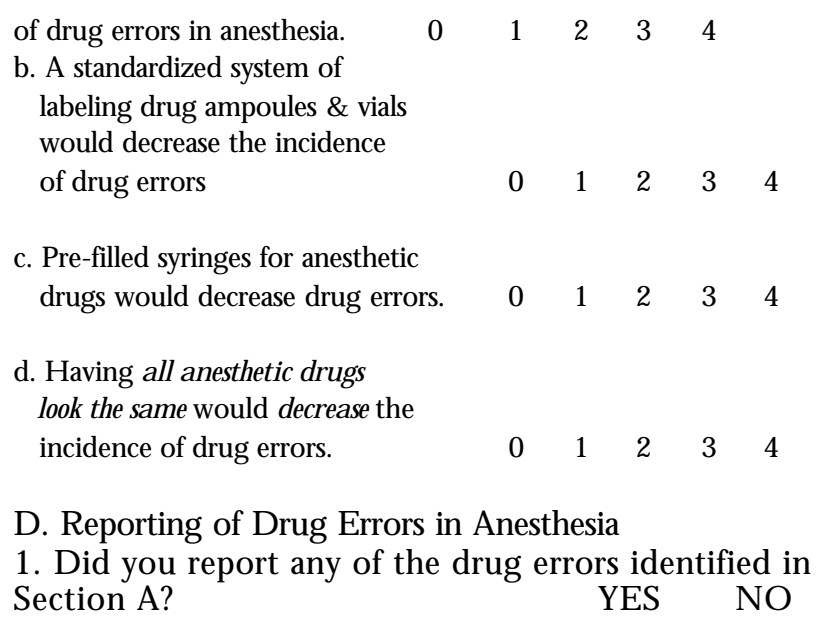

2. If yes, to whom or where did you report the error(s)?

3. If you did not report the error(s), why not? (Check one or more.) Error was inconsequential

--- Concern regarding the opinion of colleagues

--- N ot certain to whom or where the report should go

-_-_ Concern regarding the medical-legal risks involved

comments: O ther implications of reporting the error

4. Was the patient notified of the drug error?

$$
\text { EVENT NUMBER }
$$

Yes

$\begin{array}{lll}1 & 2 & 3\end{array}$

No

5. If there were a single reporting agency for anesthetic drug errors, would you have reported the error(s) to this agency?

YES NO

6. What steps (if any) were taken to prevent such a drug error from occurring again?

Explain:

\section{References}

1 Leape LL, Brennan TA, Laird N, et al. The nature of adverse events in hospitalized patients. Results of the $\mathrm{H}$ arvard M edical Practice Study II. N Engl J M ed 1991; 324: 377-84.

2 Bates DW, Cullen DJ, Laird N, et al. Incidence of adverse drug events and potential adverse drug events. I mplications for prevention. JAM A 1995; 274: 29-34.

3 Schneider PJ, Gift M G, LeY-P, R othermich EA, Sill $\mathrm{BE}$. Cost of medication-related problems at a university hospital. Am J H ealth Syst Pharm 1995; 52: 2415-8.
4 Chopra V, Bovill J G, Spierdijk J, K oornneef F, Reported significant observations during anaesthesia: a prospective analysis over an 18-month period. $\mathrm{Br} J$ Anaesth 1992; 68: 13-7.

5 Short TG, O'R egan A, Lew J, Oh TE. Critical incident reporting in an anaesthetic department quality assurance programme. Anaesthesia 1992; 47: 3-7.

6 Cooper JB, N ewbower RS, Kitz RJ. An analysis of major errors and equipment failures in anesthesia management: considerations for prevention and detection. Anesthesiology 1984; 60: 34-42.

7 Currie M, Mackay P, M organ C, et al. The "wrong drug" problem in anaesthesia: an analysis of 2000 incident reports. Anaesth Intensive C are 1993; 21: 596-601.

8 Tesser MJ, White I, N augler-Colville M, Biehl DR. Inadvertent epidural administration of potassium chloride. A case report. Can J Anaesth 1988; 35: 631-3.

9 Symington MJ, M urthy BV, Milligan K R. Epidural mexilitine (Letter). Anaesthesia 1993; 48: 925.

10 Ziser A, Sorenson EJ, Bluestein LS, R onan KP. Epidural injection of aztreonam (Letter). Can J Anaesth 1994; 41: 553.

11 GroudineSB. U nexpected results: consider a medication error (Letter). Anesth Analg 1992; 75: 1073-4.

12 Orser BA, Oxorn DC. An anaesthetic drug error: minimizing the risk. Can J Anaesth 1994; 41: 120-4.

13 Williamson JA, Webb R K, Sellen A, R unciman WB, Van der Walt JH. H uman failure: an analysis of 2000 incident reports. Anaesth Intensive Care 1993; 21: 678-83.

14 A lbert M. Physician, $\mathrm{H}$ eal Thyself. Scientific America, $M$ ay 2000: 32-3.

15 M erry AF, Peck DJ. Anaesthetists, errors in drug administration and the law. N Z M ed J 1995; 108: 185-7.

$16 \mathrm{~K}$ ohn LT, Corrigan JM, D onaldson M S. To Err is $\mathrm{H}$ uman: Building a Safer $\mathrm{H}$ ealth System. Washington: N ational A cademy Press, 1999.

17 Orser B. Reducing medication errors. CMAJ 2000; 162: 1150-1.

18 Chen R, Orser BA. M edication labels: for whose benefit? (L etter) Can J Anaesth 1996; 43: 194-5.

19 Cullen DJ, Sweitzer BJ, Bates DW, Burdick E, Edmondson $A$, Leape LL. Preventable adverse drug events in hospitalized patients: a comparative study of intensive care and general care units. Crit Care M ed 1997; 25: 1289-97.

$20 \mathrm{~N}$ ational Patient Safety Foundation. D iverse G roups Come Together to Improve $\mathrm{H}$ ealth Care Safety Through the $\mathrm{N}$ ational Patient Safety Foundation [Web page]. 1997 Available at www.ama-assn.org/medsci/nps.

21 Orser BA. M edication safety in anesthetic practice: first do no harm. Can J Anesth 2000; (In press). 